\title{
Volumes and Heat Capacities of Cobalt(II), Nickel(II) and Copper(II) Sulfate in Aqueous Solution
}

\author{
Chandrika Akilan, ${ }^{\dagger}$ Ting Chen,$^{\dagger}$ Tuomas Vielma ${ }^{\dagger}$ Peter M. May, ${ }^{\dagger}$ Gamini \\ Senanayake ${ }^{\dagger}$ and Glenn Hefter*, ${ }^{\dagger}$
}

${ }^{\dagger}$ Chemistry Department, Murdoch University, Murdoch, Western Australia 6150, Australia

${ }^{\ddagger}$ Research Unit of Sustainable Chemistry, University of Oulu, 90014 Oulu, Finland

\begin{abstract}
Densities and isobaric volumetric heat capacities of aqueous solutions of the sulfate salts of cobalt(II), nickel(II) and copper(II) have been measured at $298.15 \mathrm{~K}$ and 0.1 MPa using vibrating tube densimetry and Picker flow calorimetry, respectively, at concentrations in the range $0.01 \lesssim m / \mathrm{mol} \cdot \mathrm{kg}^{-1} \lesssim 1.5$. These data were used to derive the corresponding apparent molar volumes, $V_{\phi}$, and apparent molar isobaric heat capacities, $C_{p \phi}$. Where comparisons were possible the present $V_{\phi}$ results were in good agreement with literature data. No $C_{p \phi}$ data appear to have been reported previously for any of these salts. The variations of $V_{\phi}$ and $C_{p \phi}$ with concentration were well correlated using the Pitzer formalism combined with values of $V^{\mathrm{o}}$ and $C_{p}{ }^{\mathrm{o}}$ estimated from literature data. Both $V_{\phi}$ and $C_{p \phi}$ for all three salts show remarkable similarities and can be shown to lie on a common line by applying fixed addends over almost the whole concentration range studied.
\end{abstract}




\section{INTRODUCTION}

Sulfate-based hydrometallurgy is widely employed for the extraction and purification of many economically-critical metals. ${ }^{1}$ For example, about $70 \%$ of the world's nickel resources occur in heavily oxidized nickel laterite ores, which are invariably digested with aqueous solutions of sulfuric acid. ${ }^{2}$ As laterite ores typically contain significant amounts of the more-valuable cobalt, the solution properties of both these metal sulfates are of special interest. Likewise, copper(II) sulfate solutions form key stages in the extraction, purification and subsequent use (eg, in electroplating) of copper. ${ }^{3}$ Solutions containing all three of these (and other) salts are also important in the treatment of acid mine drainage from old and existing mine sites. ${ }^{4}$

In addition to their vast range of applications, divalent metal sulfate solutions have attracted considerable scientific interest as archetypal higher-charged symmetrical electrolytes. ${ }^{5,6}$ Such solutions have been widely used to test the application of theories of activity coefficients, electrical conductance and the self-association of electrolyte solutions.

Numerous publications have described various aspects of the physicochemical properties of solutions of cobalt, nickel and copper sulfate solutions. ${ }^{7}$ However, there have been few modern studies of their volumetric properties and virtually no data (old or recent) are available for their heat capacities. This is unfortunate because both volumetric and heat capacity data are essential for the reliable modelling of mass and heat transfer processes required for chemical engineering purposes $^{8}$ and for environmental activities. ${ }^{4}$

This paper reports volumes and heat capacities obtained, respectively, by vibrating-tube densimetry and flow calorimetry, of aqueous solutions of the industrially-important cobalt(II), nickel(II) and copper(II) sulfates up to high concentrations at $298.15 \mathrm{~K}$.

\section{EXPERIMENTAL SECTION}

2.1 Materials. The sources and purities of the three metal sulfates are summarized in Table 1. Briefly, $\mathrm{CoSO}_{4} \cdot 7 \mathrm{H}_{2} \mathrm{O}$ and $\mathrm{NiSO}_{4} \cdot 6 \mathrm{H}_{2} \mathrm{O}$ were recrystallized twice from aqueous solution; commercial $\mathrm{CuSO}_{4} \cdot 5 \mathrm{H}_{2} \mathrm{O}$ was used as received. Stock solutions prepared from these solids were adjusted to $\mathrm{pH}=4.0 \pm 0.5$, by the addition of trivial amounts of sulfuric acid, to restrict both cation hydrolysis ${ }^{11}$ and protonation of the anion. ${ }^{12}$ These solutions were then filtered (Millipore, USA, $0.45 \mu \mathrm{m})$ and assayed $( \pm 0.2 \%)$ by complexometric titration against EDTA (BDH, UK, Concentrated Volumetric Standard).${ }^{13}$ More dilute solutions were prepared by weight, without buoyancy corrections. The concentrations studied cover up to approximately $(50,60$ and 80$) \%$ of the saturation concentrations at $298 \mathrm{~K}$ for the (Co, $\mathrm{Ni}$ and $\mathrm{Cu}$ ) sulfates respectively. Solutions of sodium chloride (used for calibration purposes) were prepared individually by weight from $\mathrm{NaCl}(\mathrm{s})$ that had been dried overnight at $450 \mathrm{~K}$ under vacuum. All solutions were prepared using freshly degassed high purity water (Millipore Milli-Q system). 
Table 1. Sample Sources and Purities

\begin{tabular}{|c|c|c|c|c|c|c|}
\hline chemical name & CASRN & source & $\begin{array}{l}\text { initial mass } \\
\text { fraction } \\
\text { purity }\end{array}$ & $\begin{array}{l}\text { purification } \\
\text { method }\end{array}$ & $\begin{array}{l}\text { final ma } \\
\text { fraction } \\
\text { purity }\end{array}$ & analysis method \\
\hline cobalt sulfate & $10026-24-1$ & & & recrystallisation & & complexometric \\
\hline heptahydrate & & Sigma & $\geq 0.99$ & from water & 0.998 & titration \\
\hline nickel sulfate & $10101-97-0$ & & & recrystallisation & & complexometric \\
\hline hexahydrate & & Aldrich & $\geq 0.9999^{a}$ & from water & 0.998 & titration \\
\hline copper sulfate & $7758-99-8$ & & & & & complexometric \\
\hline pentahydrate & & Biolab & $\geq 0.98$ & none & 0.998 & titration \\
\hline sodium chloride & $7440-23-5$ & APS & $\geq 0.999$ & none & - & - \\
\hline EDTA, disodium salt & $6381-92-6$ & $\mathrm{BDH}$ & $\geq 0.998^{b}$ & none & - & - \\
\hline
\end{tabular}

${ }^{a}$ On a metals basis only. ${ }^{b}$ Commercial Concentrated Volumetric Standard solution.

2.2 Instrumentation. Solution densities, $\rho$, were measured with a vibrating glass-tube densimeter (Anton Paar, Austria, Model DMA02D) fitted with an Anton Paar mPDS4000 data module. The temperature of the vibrating tube was controlled to $298.15 \pm 0.01 \mathrm{~K}$, with a NISTtraceable accuracy of $0.02 \mathrm{~K}$, using a circulating thermostat (Haake, Germany, Model K20). The densimeter was calibrated with high purity water and dry air assuming literature densities $^{9,10}$ of $0.997047 \mathrm{~g} \cdot \mathrm{cm}^{-3}$ and $1.1850 \mathrm{mg} \cdot \mathrm{cm}^{-3}$ at $298.15 \mathrm{~K}$ and a pressure of $101 \pm 1$ $\mathrm{kPa}$. Densities for $\mathrm{CoSO}_{4}(\mathrm{aq})$ and $\mathrm{NiSO}_{4}(\mathrm{aq})$ were reproducible to $\pm 10 \mu \mathrm{g} \cdot \mathrm{cm}^{-3}$, and for $\mathrm{CuSO}_{4}(\mathrm{aq})$ to $\pm 15 \mu \mathrm{g} \cdot \mathrm{cm}^{-3}$.

Isobaric volumetric heat capacities, $\sigma_{p}$, were measured with a Picker flow calorimeter (Sodev, Canada, Model CP-C) using a base power of $20 \mathrm{~mW}$ and a sensitivity of $3 \mathrm{~mW}$, corresponding to an average measurement temperature of $298.15 \pm 0.065 \mathrm{~K}$. Temperatures outside the immediate measurement zone were controlled to $\pm 0.005 \mathrm{~K}$ using a Sodev circulator-thermostat Model CT-L. Liquids were introduced into the calorimeter via a four-way chromatography valve (Hamilton, USA, Model HVP). The flow rate was maintained at $\sim 0.6 \mathrm{~cm}^{3} \cdot \mathrm{min}^{-1}$ using a peristaltic pump (Gilson, USA, Minipuls 3). All measurements reported are 'first leg' values, ${ }^{15}$ corresponding to the displacement of water in the calorimeter by solution. Further details of the operation of the calorimeter are given elsewhere. ${ }^{14,15}$

2.3 Calculations. Density differences, $\Delta \rho$, were obtained from the operational densimeter equation:

$$
\Delta \rho=\rho-\rho_{\mathrm{o}}=k\left(\tau^{2}-\tau_{\mathrm{o}}^{2}\right)
$$

where $k$ is a calibration constant, $\tau$ is the oscillation period of the vibrating tube and the subscript ${ }_{\text {o }}$ denotes a pure water quantity. Apparent molar volumes, $V_{\phi}$, were calculated via the usual equation:

$$
V_{\phi}=\left(M_{\mathrm{s}} / \rho\right)-\left\{\left(\rho-\rho_{\mathrm{o}}\right) / m \rho \rho_{\mathrm{o}}\right\}
$$

where $M_{\mathrm{s}}$ is the molar mass of the anhydrous solute $\left(155.00,154.75\right.$ and $159.61 \mathrm{~g} \cdot \mathrm{mol}^{-1}$ for $\mathrm{CoSO}_{4}, \mathrm{NiSO}_{4}$ and $\mathrm{CuSO}_{4}$ respectively) and $m$ is its concentration (molality) in mol $\cdot \mathrm{kg}^{-1}$. 
Isobaric massic heat capacities, $c_{p}$, were calculated as $c_{p}=\sigma_{p} / \rho$ from the measured isobaric volumetric heat capacities and the present experimental densities. Isobaric apparent molar heat capacities, $C_{p} \phi$, were then obtained as:

$$
C_{p \phi}=c_{p} M_{\mathrm{s}}+\left\{\left(c_{p}-c_{p \mathrm{o}}\right) / m\right\}
$$

where the isobaric massic heat capacity of pure water at $298.15 \mathrm{~K}$ and $101 \mathrm{kPa}, c_{p o}=4.1813$ $\mathrm{J} \cdot \mathrm{K}^{-1} \cdot \mathrm{g}^{-1}$, was calculated from the IAPWS-95 equation of state. ${ }^{9}$

The operating protocols of both the densimeter and the calorimeter were verified by measurements on ca. eight $\mathrm{NaCl}(\mathrm{aq})$ solutions over the range $0.5 \lesssim m / \mathrm{mol} \cdot \mathrm{kg}^{-1} \lesssim 5$. The values of $V_{\phi}$ and $C_{p \phi}$ obtained agreed with those calculated using Archer's equation ${ }^{16}$ within the experimental uncertainties.

\section{RESULTS AND DISCUSSION}

The measured density differences, $\Delta \rho$, and relative isobaric volumetric heat capacity changes, $\Delta \sigma / \sigma$, for the aqueous solutions of the three metal sulfate salts are listed in Table 2. All reported values are the average of at least two independent measurements. Also shown in Table 2 are the corresponding apparent molar quantities, $V_{\phi}$ and $C_{p \phi}$, calculated via eqs 2 and 3 respectively, and their combined standard uncertainties $u_{c}$, which were estimated using the GUM convention. ${ }^{17}$ The values of $V_{\phi}$ and $C_{p \phi}$ so obtained varied smoothly over the investigated concentration ranges (Figures 1-4), with no evidence of the slight 'waviness' often observed in such plots for aqueous electrolyte solutions. ${ }^{18}$ For the convenience of potential users, equations that relate $\rho$ and $c_{p}$ to molality for each of the three sets of solutions are given in the Supplementary Information.

Table 2. Experimental Density $(\Delta \rho)$ and Relative Isobaric Volumetric Heat Capacity $(\Delta \sigma \sigma)$ Differences Along with Apparent Molar Volumes $\left(V_{\phi}\right)$ and Isobaric Massic $\left(c_{p}\right)$ and Apparent Molar $\left(C_{p \phi}\right)$ Heat Capacities for $\mathrm{CoSO}_{4}(\mathrm{aq})$, $\mathrm{NiSO}_{4}(\mathrm{aq})$ and $\mathrm{CuSO}_{4}(\mathrm{aq})$ at 298.15 K and 0.101 $\mathrm{MPa}^{a}$

\begin{tabular}{lccccc}
\hline $\begin{array}{c}m \\
/ \mathrm{mol} \cdot \mathrm{kg}^{-1}\end{array}$ & $\begin{array}{c}10^{3} \Delta \rho \\
/ \mathrm{g} \cdot \mathrm{cm}^{-3}\end{array}$ & $\begin{array}{c}V_{\phi}^{b} \\
/ \mathrm{cm}^{3} \cdot \mathrm{mol}^{-1}\end{array}$ & $10^{3} \Delta \sigma \sigma$ & $\begin{array}{c}c_{p} \\
/ \mathrm{J} \cdot \mathrm{K}^{-1} \cdot \mathrm{g}^{-1}\end{array}$ & $\begin{array}{c}C_{p \phi}{ }^{b} \\
/ \mathrm{J} \cdot \mathrm{K}^{-1} \cdot \mathrm{mol}^{-1}\end{array}$ \\
\hline $\mathbf{C o S O}$ & & & & & \\
0.00988 & $1.606(4)$ & $-8.05 \pm 0.59$ & $-0.522(23)$ & $4.1724(1)$ & $-254.5 \pm 11.6$ \\
0.02064 & $3.326(3)$ & $-6.62 \pm 0.38$ & $-1.034(4)$ & $4.1631(1)$ & $-236.9 \pm 3.5$ \\
0.02673 & $4.295(4)$ & $-6.15 \pm 0.37$ & $-1.291(4)$ & $4.1580(1)$ & $-227.6 \pm 2.9$ \\
0.04798 & $7.670(4)$ & $-5.31 \pm 0.33$ & $-2.169(2)$ & $4.1404(1)$ & $-211.1 \pm 2.1$ \\
0.07637 & $12.130(6)$ & $-4.27 \pm 0.33$ & $-3.310(13)$ & $4.1174(1)$ & $-198.9 \pm 2.0$ \\
0.1057 & $16.721(8)$ & $-3.69 \pm 0.32$ & $-4.444(5)$ & $4.0941(1)$ & $-191.2 \pm 1.8$ \\
0.2058 & $32.179(8)$ & $-1.75 \pm 0.31$ & $-7.888(2)$ & $4.0186(1)$ & $-167.4 \pm 1.6$ \\
0.3495 & $54.096(6)$ & $0.23 \pm 0.30$ & $-12.06(2)$ & $3.9183(1)$ & $-145.3 \pm 1.5$ \\
0.5343 & $81.756(7)$ & $1.42 \pm 0.28$ & $-16.67(2)$ & $3.8000(1)$ & $-124.6 \pm 1.4$ \\
0.6826 & $103.662(8)$ & $2.44 \pm 0.28$ & $-19.52(3)$ & $3.7136(1)$ & $-109.6 \pm 1.4$ \\
0.8781 & $132.253(7)$ & $3.49 \pm 0.27$ & $-21.94(4)$ & $3.6106(2)$ & $-90.3 \pm 1.3$ \\
0.9937 & $148.792(8)$ & $4.20 \pm 0.26$ & $-24.34(5)$ & $3.5498(2)$ & $-85.3 \pm 1.3$
\end{tabular}




$\begin{array}{llllll}1.2241 & 181.716(8) & 5.18 \pm 0.25 & -26.83(2) & 3.4418(1) & -70.6 \pm 1.2\end{array}$

\section{$\mathrm{NiSO}_{4}$}

$\begin{array}{lccccc}0.01021 & 1.683(4) & -10.59 \pm 0.58 & - & - & - \\ 0.01957 & 3.215(6) & -10.02 \pm 0.47 & -1.066(13) & 4.1634(1) & -269.5 \pm 4.6 \\ 0.03408 & 5.578(2) & -9.38 \pm 0.34 & -1.645(8) & 4.1512(1) & -240.9 \pm 2.6 \\ 0.05156 & 8.407(3) & -8.74 \pm 0.33 & -2.352(2) & 4.1366(1) & -227.1 \pm 2.1 \\ 0.07709 & 12.529(6) & -8.18 \pm 0.33 & -3.404(20) & 4.1154(1) & -218.6 \pm 2.2 \\ 0.1079 & 17.438(2) & -7.22 \pm 0.32 & -4.551(3) & 4.0907(1) & -206.3 \pm 1.8 \\ 0.2103 & 33.712(7) & -5.89 \pm 0.31 & -8.144(16) & 4.0116(1) & -186.3 \pm 1.7 \\ 0.3649 & 57.758(7) & -3.80 \pm 0.30 & -12.60(1) & 3.9025(1) & -160.0 \pm 1.5 \\ 0.5735 & 89.784(5) & -2.09 \pm 0.29 & -17.90(1) & 3.7672(1) & -139.0 \pm 1.4 \\ 0.8417 & 130.079(6) & -0.22 \pm 0.28 & -22.66(2) & 3.6149(1) & -113.5 \pm 1.4 \\ 1.014 & 155.730(7) & 0.62 \pm 0.27 & -25.36(2) & 3.5247(1) & -102.1 \pm 1.3 \\ 1.211 & 184.320(6) & 1.73 \pm 0.26 & -27.80(2) & 3.4308(1) & -89.0 \pm 1.2 \\ 1.525 & 230.274(9) & 2.70 \pm 0.25 & -30.95(6) & 3.2917(2) & -74.0 \pm 1.2\end{array}$

\section{$\mathrm{CuSO}_{4}$}

0.00993

$\begin{array}{ccccc}1.656(1) & -7.61 \pm 0.45 & -0.370(1) & 4.1728(1) & -187.3 \pm 6.1 \\ 8.102(2) & -3.94 \pm 0.33 & -1.624(16) & 4.1409(1) & -153.1 \pm 2.4 \\ 16.167(2) & -2.51 \pm 0.32 & -2.916(7) & 4.1026(1) & -132.3 \pm 1.7 \\ 18.670(9) & -1.65 \pm 0.33 & -3.345(11) & 4.0907(1) & -127.3 \pm 1.7 \\ 39.399(3) & 0.14 \pm 0.31 & -5.859(14) & 3.9988(1) & -98.3 \pm 1.5 \\ 47.460(18) & 0.7 \pm 0.31 & -6.725(5) & 3.9645(1) & -91.0 \pm 1.5 \\ 78.404(16) & 2.14 \pm 0.29 & -9.103(18) & 3.8412(1) & -67.3 \pm 1.4 \\ 90.684(31) & 3.01 \pm 0.29 & -9.848(8) & 3.7950(1) & -58.3 \pm 1.3 \\ 101.012(14) & 3.43 \pm 0.28 & -10.22(2) & 3.7578(1) & -51.6 \pm 1.3 \\ 152.948(34) & 5.40 \pm 0.27 & -11.30(1) & 3.5842(1) & -25.0 \pm 1.2 \\ 157.799(24) & 5.80 \pm 0.27 & -11.24(2) & 3.5694(1) & -21.5 \pm 1.2 \\ 163.996(12) & 6.05 \pm 0.26 & -11.50(1) & 3.5494(1) & -19.7 \pm 1.2\end{array}$

0.04968

0.1000

0.1161

0.2478

0.2996

0.4999

0.5818

0.6501

1.000

1.035

$163.996(12) \quad 6.05 \pm 0.26$

$-11.50(1) \quad 3.5494(1)$

$-19.7 \pm 1.2$

${ }^{a}$ Standard uncertainties $u$ are $u_{\mathrm{r}}(m)=0.002 \mathrm{~mol} \cdot \mathrm{kg}^{-1}, u(T)=0.01 \mathrm{~K}, u(p)=0.001 \mathrm{MPa}$. Numbers in parentheses are the standard uncertainties $u$ in the quantities calculated as the standard deviations of replicate measurements. ${ }^{b}$ Average \pm combined standard uncertainty $u$.

3.1 Apparent Molar Volumes. The present values of $V_{\phi}$ for $\mathrm{CoSO}_{4}(\mathrm{aq}), \mathrm{NiSO}_{4}(\mathrm{aq})$ and $\mathrm{CuSO}_{4}(\mathrm{aq})$ are plotted against concentration (as $\sqrt{ } m$ ) in Figures 1, 2 and 3 respectively, along with the available literature data. For $\mathrm{CoSO}_{4}(\mathrm{aq})$ the present results (Figure 1) are in excellent agreement with those of Lo Surdo and Millero, ${ }^{19}$ also obtained by vibrating tube densimetry (vtd), with an average difference of better than $\pm 0.2 \mathrm{~cm}^{3} \cdot \mathrm{mol}^{-1}$. The older data of Cantelo and Phifer, ${ }^{20}$ measured using the less precise pycnometric method, are clearly in error. For $\mathrm{NiSO}_{4}(\mathrm{aq})$ the present results (Figure 2) are in good agreement with the values reported both by Lo Surdo and Millero ${ }^{19}$ and by Isono (also using vtd ${ }^{21}$ with average differences of \pm 0.1 and $\pm 0.5 \mathrm{~cm}^{3} \cdot \mathrm{mol}^{-1}$, respectively, over the studied concentration range. The situation for $\mathrm{CuSO}_{4}(\mathrm{aq})$ is slightly more complicated (Figure 3). There are three data sets: that of Pearce and Pumplin ${ }^{22}$ obtained by pycnometry and the more recent values of Lo Surdo and Millero, ${ }^{19}$ using a magnetic float, and of Puchalska et al. ${ }^{23}$ using vtd. While the present data are in good agreement 
with the older values and those of Lo Surdo and Millero, ${ }^{19}$ differing on average by \pm 0.4 $\mathrm{cm}^{3} \cdot \mathrm{mol}^{-1}$, the results reported by Puchalska et al. ${ }^{23}$ differ by $\sim 2 \mathrm{~cm}^{3} \cdot \mathrm{mol}^{-1}$ over most of the common concentration range. Similar deviations of $V_{\phi}$ values reported by Puchalska et al. from those of other investigators have also been observed for $\mathrm{ZnSO}_{4}(\mathrm{aq}){ }^{24}$ It is interesting to note that $V_{\phi}\left(m^{1 / 2}\right)$ for all three of the present systems become almost linear, and with the same slopes, when $m^{1 / 2} \gtrsim 0.2\left(\mathrm{~mol} \cdot \mathrm{kg}^{-1}\right)^{1 / 2}$ (see also Section 3.4. below).

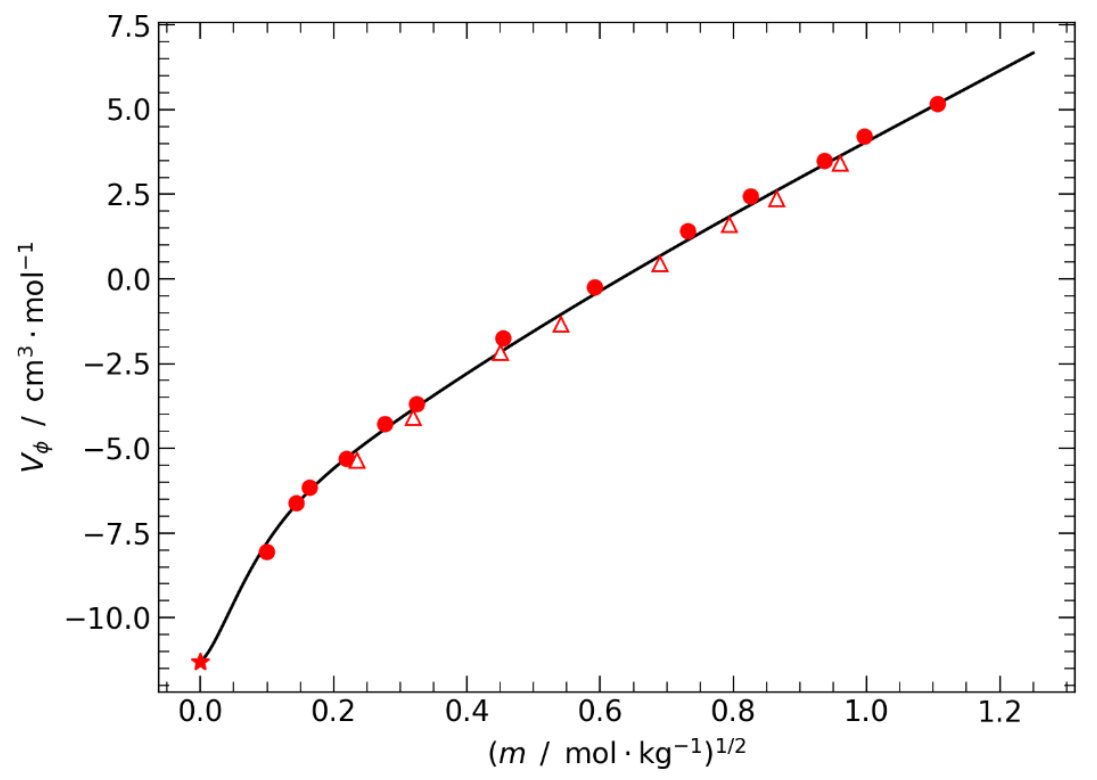

Figure 1. Present and literature values for the apparent molar volume, $V_{\phi}$, of $\mathrm{CoSO}_{4}(\mathrm{aq})$ as a function of solute concentration (as $\sqrt{ } m$ ) at $298.15 \mathrm{~K}$ and $0.1 \mathrm{MPa}: \bullet$, this work; $\Delta$, Lo Surdo and Millero, ${ }^{19} \star, V^{\circ}$ calculated using Marcus's ionic values. ${ }^{25}$ The solid line was calculated from the present Pitzer model (Section 3.4.) using both data sets. 


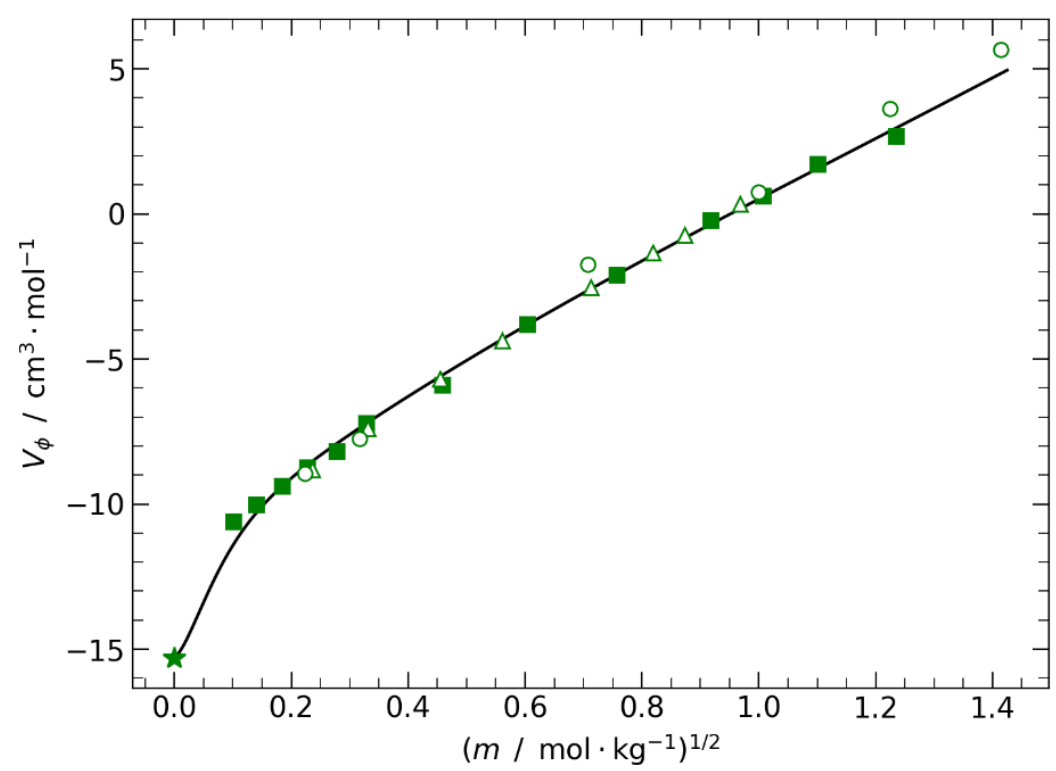

Figure 2. Present and literature values for the apparent molar volume, $V_{\phi}$, of $\mathrm{NiSO}_{4}(\mathrm{aq})$ as a function of solute concentration (as $\sqrt{ } m$ ) at $298.15 \mathrm{~K}$ and $0.1 \mathrm{MPa} \mathbf{m}$, this work; ○, Isono; ${ }^{20} \Delta$, Lo Surdo and Millero; ${ }^{19} \star, V^{\circ}$ calculated from Chen's value for $\mathrm{Ni}^{2+}(\mathrm{aq})^{14}$ and Marcus's value for $\mathrm{SO}_{4}{ }^{2-}(\mathrm{aq}){ }^{25}$ The solid line was calculated from the present Pitzer model (Section 3.4.) using both data sets.

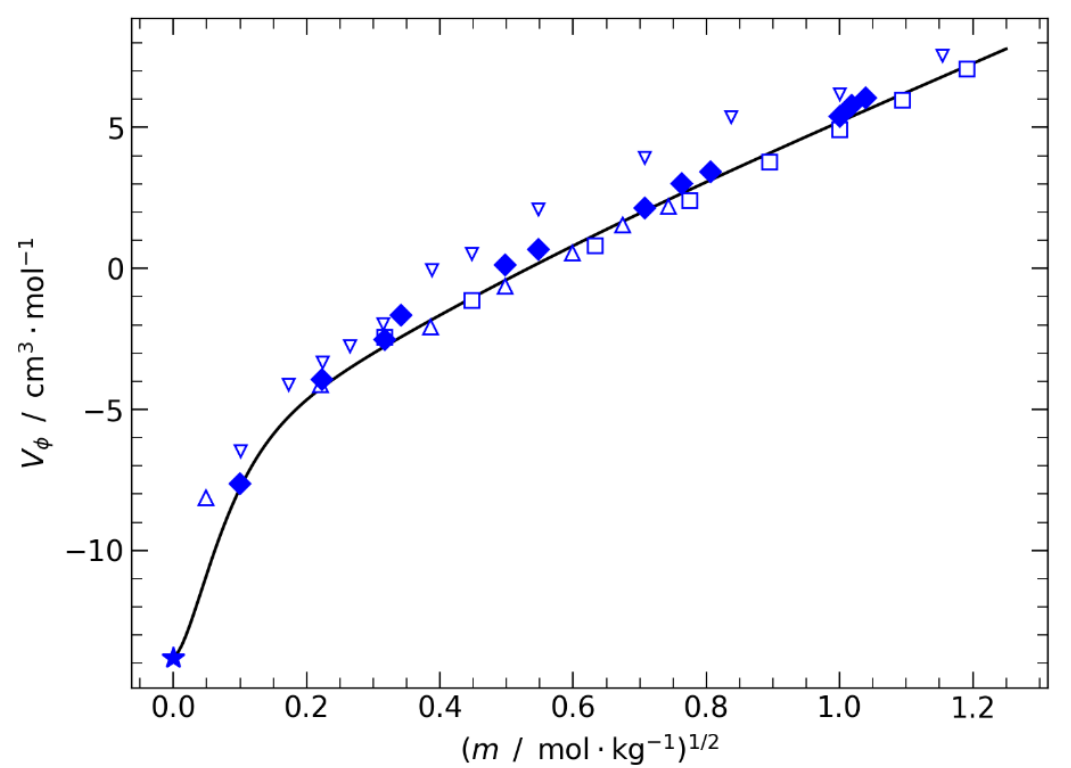

Figure 3. Present and literature values for the apparent molar volume, $V_{\phi}$, of $\mathrm{CuSO}_{4}(\mathrm{aq})$ as a function of solute concentration (as $\sqrt{ } m$ ) at $298.15 \mathrm{~K}$ and $0.1 \mathrm{MPa}$ : this work; $\Delta$, Lo Surdo and Millero; ${ }^{19} \square$, Pearce and Pumplin; ${ }^{22} \nabla$, Puchalska et al. ${ }^{23} \star, V^{\circ}$ calculated from the Spitzer 
et al. value for $\mathrm{Cu}^{2+}(\mathrm{aq})^{26}$ and Marcus's value for $\mathrm{SO}_{4}{ }^{2-}(\mathrm{aq}){ }^{25}$ The solid line was calculated from the present Pitzer model (Section 3.4.) using all data except those of Puchalska et al. ${ }^{23}$

3.2 Apparent Molar Heat Capacities. The apparent molar isobaric heat capacities, $C_{p \phi}$, for the present salts (Table 2) are plotted together in Figure 4 as a function of the solute concentration (as $\sqrt{ } m$ ). As noted in the Introduction there are, to the best of our knowledge, no reliable literature data with which to compare our values. A partial exception is the batch calorimetry study of $\mathrm{CuSO}_{4}(\mathrm{aq})$ by Kapustinskii et al. ${ }^{27}$ However, these values have been rejected as being seriously in error in a critical review of thermodynamic data for $\mathrm{CuSO}_{4}(\mathrm{aq})$ by Höffler and Steiger. ${ }^{28}$

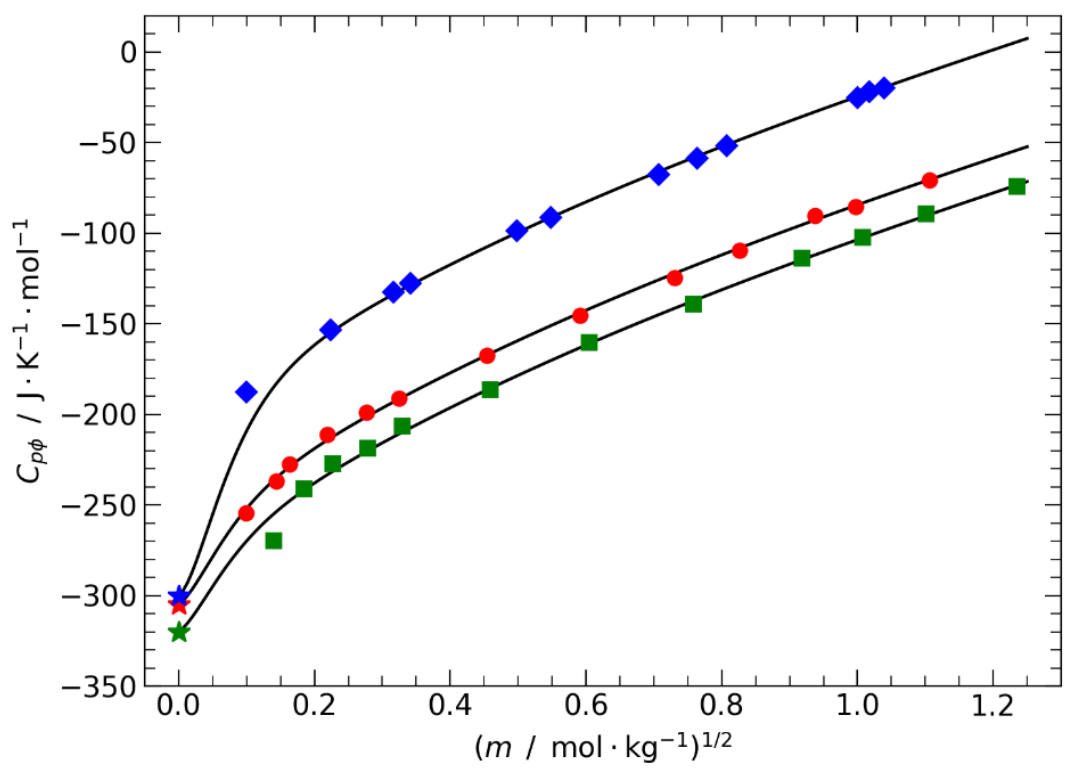

Figure 4. Present values for the apparent molar heat capacities, $C_{p \phi}$, of divalent metal sulfates as a function of solute concentration (as $\sqrt{ } m$ ) at $298.15 \mathrm{~K}$ and $0.1 \mathrm{MPa}$ : blue $\downarrow, \mathrm{CuSO}_{4}(\mathrm{aq})$; red •, $\mathrm{CoSO}_{4}(\mathrm{aq})$; green $\mathbf{\square}, \mathrm{NiSO}_{4}(\mathrm{aq}) ; \star, C_{p}{ }^{\circ}$ calculated from Marcus's ionic values. ${ }^{25}$ The solid lines were calculated from the present Pitzer models (Section 3.4.).

3.3 Standard Molar Values. Standard state (infinite dilution) values of the volumes and heat capacities, $V^{\circ}$ and $C_{p}{ }^{\circ}$, for the present salts can in principle be obtained by fitting $Y_{\phi}(m)$ data $(Y$ $=V$ or $C_{p}$ ) with an appropriate theoretical model and extrapolating it to infinite dilution. ${ }^{29}$ The most common models used for this purpose are the (extended) Redlich-Rosenfeld-Meyer equation(s) $)^{30,31}$ and the Pitzer equation(s). ${ }^{32}$ Both of these models are semi-empirical but, while they can provide excellent fits of $Y_{\phi}(m)$ data at moderate and high concentrations, it is well known that they do not provide reliable estimates of $Y^{\circ}$ for 2:2 electrolytes. ${ }^{33,34}$ A major reason for this unfortunate characteristic is the presence of significant self-association (ion pairing), which occurs in such systems even at low solute concentrations. The nature of ion pairs formed in divalent metal sulfate solutions is complicated ${ }^{35,36}$ and their presence in appreciable amounts can have substantial effects on observed $Y_{\phi}(m)$ values at low $m$, producing an unreliable extrapolation to infinite dilution. ${ }^{32,33,37}$

While attempts have been made to quantitatively incorporate ion association into the estimation of $Y^{\mathrm{o}}$ values, ${ }^{38,39}$ the extra (mostly unknown) parameters required and the numerical 
correlations among them have discouraged their widespread application. For the present salts, the $Y^{\mathrm{O}}$ was instead obtained by summation of literature values for $\mathrm{M}^{2+}(\mathrm{aq})$ and $\mathrm{SO}_{4}{ }^{2-}(\mathrm{aq})$ ions. These values are based on measurements of appropriate 1:2 and 2:1 electrolytes, for which ion pairing effects are less problematic (albeit not entirely absent). Values of $Y^{\mathrm{O}}$ (ion) were taken from Marcus $^{25}$ except where more reliable estimates were available.

3.4 Pitzer modelling. The Pitzer ion-interaction model has been widely employed for correlating the various thermodynamic properties of aqueous electrolyte solutions. The Pitzer equations for $V_{\phi}$ and $C_{p \phi}$ of a binary electrolyte solution are: ${ }^{32}$

$$
\begin{aligned}
& V_{\phi}=V_{\mathrm{MX}}^{\mathrm{o}}+v\left|z_{\mathrm{M}} z_{\mathrm{X}}\right| A_{V} \frac{\ln \left(1+1.2 \cdot I^{1 / 2}\right)}{2.4}+2 v_{\mathrm{M}} v_{\mathrm{X}} R T\left[m B_{\mathrm{MX}}^{V}+v_{\mathrm{M}} z_{\mathrm{M}} m^{2} C_{\mathrm{MX}}^{V}\right] \\
& C_{p \phi}=C_{p, \mathrm{MX}}^{\mathrm{o}}+v\left|z_{\mathrm{M}} z_{\mathrm{X}}\right| A_{J} \frac{\ln \left(1+1.2 \cdot I^{1 / 2}\right)}{2.4}-2 v_{\mathrm{M}} v_{\mathrm{X}} R T^{2}\left[m B_{\mathrm{MX}}^{J}+v_{\mathrm{M}} z_{\mathrm{M}} m^{2} C_{\mathrm{MX}}^{J}\right]
\end{aligned}
$$

where $v_{M}$ and $v_{X}$ are the stoichiometric numbers of cations $M$ and anions X per formula unit, with $v=v_{M}+v_{X}$. The quantities $z_{M}$ and $z X$ are the (algebraic) charge numbers of the ions and $A_{V}$ and $A_{J}$ are the Debye-Hückel slopes for volumes and heat capacities, respectively, calculated from the formulation of Fernandez et al. ${ }^{40}$

The second virial coefficients $B_{\mathrm{MX}}^{Y},(Y=V$ or $J)$ are empirical functions; for 2:2 electrolytes they are given by

$B_{\mathrm{MX}}^{Y}=\beta_{\mathrm{MX}}^{(0) Y}+\beta_{\mathrm{MX}}^{(1) Y} g\left(1.4 \cdot I^{1 / 2}\right)+\beta_{\mathrm{MX}}^{(2) Y} g\left(12 \cdot I^{1 / 2}\right)$

where

$g(x)=\frac{2(1-(1+x)) e^{-x}}{x^{2}}$

and $\beta_{\mathrm{MX}}^{(\mathrm{i}) Y}$ are empirical parameters, normally determined by fitting to experimental data. In this work, inclusion of the third virial coefficients, $C_{\mathrm{MX}}^{Y}$, was found to be unnecessary due to the limited concentration range of the data. The model parameters for eq 4 were fitted using the present volumetric data combined with the results of Pearce and Pumplin, ${ }^{22}$ Lo Surdo and Millero ${ }^{19}$ and Isono. ${ }^{21}$ The values reported by Puchalska et al. ${ }^{23}$ for $\mathrm{CuSO}_{4}(\mathrm{aq})$ were excluded because of their large deviations from all other data, as discussed above. For heat capacities the Pitzer parameters for eq 5 were obtained by fitting only the present results.

During the fitting process remarkable similarities in the trends of $V_{\phi}(m)$ and $C_{p \phi}(m)$ for the studied metal sulfates, became apparent (see below). Close inspection of the data shows that the behavior of the different salts differs only at low concentrations $\left(\lesssim 0.04 \mathrm{~mol} \cdot \mathrm{kg}^{-1}\right.$ ), where $\beta_{\mathrm{MX}}^{(2) Y}$ has a significant effect. It was therefore decided, for comparison purposes, to fit the Pitzer equations using common values of $\beta_{\mathrm{MX}}^{(0) Y}$ and $\beta_{\mathrm{MX}}^{(1) Y}$ for all three salts, in addition to individual fits.

No significant differences were found between the results of the two fitting strategies, and as such, only the Pitzer parameters of the preferable (simpler) fit are given here (Table 3). This set of parameters reproduces the selected $V_{\phi}$ data with an average deviation of $\pm 0.25 \mathrm{~cm}^{3} \cdot \mathrm{mol}^{-}$ ${ }^{1}$, corresponding to $\pm 0.02 \%$ (relative) in $\rho$; the smallest deviations occur for $\mathrm{CoSO}_{4}(\mathrm{aq})$ and the largest for $\mathrm{CuSO}_{4}(\mathrm{aq})$, for which the experimental data scatter is also greatest. For the heat 
capacity data, after excluding the most dilute (and most uncertain) point for $\mathrm{CuSO}_{4}(\mathrm{aq})$ and $\mathrm{NiSO}_{4}(\mathrm{aq})$, the average deviation was $\pm 1.2 \mathrm{~J} \cdot \mathrm{K}^{-1} \cdot \mathrm{mol}^{-1}$ in $C_{p \phi}$ and $\pm 0.02 \%$ (relative) in $c_{p}$. Such differences are well within the experimental uncertainties.

Table 3. Debye-Hückel Slopes, Selected $V^{\circ}$ and $C_{p}{ }^{\circ}$ and Fitting Parameters for Eqs 4 and 5 at 298.15 $\mathrm{K}$ and $0.1 \mathrm{MPa}^{a, b}$

\begin{tabular}{cccc}
\hline$A_{V}$ & 1.8978 & $A_{J}$ & 31.77 \\
$V_{\mathrm{CoSO}_{4}}^{\circ}$ & -11.3 & $C_{p, \mathrm{CoSO}_{4}}^{\circ}$ & -305 \\
$V_{\mathrm{NiSO}_{4}}^{\circ}$ & -15.3 & $C_{p, \mathrm{NiSO}_{4}}^{\circ}$ & -320 \\
$V_{\mathrm{CuSO}_{4}}^{\circ}$ & -11.1 & $C_{p, \mathrm{CuSO}_{4}}^{\circ}$ & -300 \\
$\beta_{\mathrm{MSO}_{4}}^{(0) V}$ & 0.0004625 & $\beta_{\mathrm{MSO}_{4}}^{(0) J}$ & $-1.557 \cdot 10^{-5}$ \\
$\beta_{\mathrm{MSO}_{4}}^{(1) V}$ & 0.002386 & $\beta_{\mathrm{MSO}_{4}}^{(1) J}$ & $-8.086 \cdot 10^{-5}$ \\
$\beta_{\mathrm{CoSO}_{4}}^{(2) V}$ & 0.1725 & $\beta_{\mathrm{CoSO}_{4}}^{(2) J}$ & -0.008598 \\
$\beta_{\mathrm{NiSO}_{4}}^{(2) V}$ & 0.2009 & $\beta_{\mathrm{NiSO}_{4}}^{(2) J}$ & -0.007885 \\
$\beta_{\mathrm{CuSO}_{4}}^{(2) V}$ & 0.2317 & $\beta_{\mathrm{CuSO}_{4}}^{(2) J}$ & -0.01936 \\
\hline
\end{tabular}

${ }^{a}$ Units for the quantities presented here correspond to Eqs 4 and 5 expressed in $\mathrm{cm}^{3} \cdot \mathrm{mol}^{-1}$ and $\mathrm{J} \cdot \mathrm{K}^{-1} \cdot \mathrm{mol}^{-1}$, respectively. ${ }^{b}$ See text for details of $V^{\circ}$ and $C_{p}{ }^{\circ}$ values.

3.5 Comparative Behaviour of the Divalent Metal Sulfates. A well-known feature of the aqueous solutions of the divalent metal sulfates is their similarities to each other. This behaviour includes association constants and other thermodynamic data, ${ }^{5}$ spectroscopic behaviour ${ }^{42}$ and even dielectric properties. ${ }^{35,36}$ For the divalent first-row transition metal salts this peculiarity persists in spite of the differing sizes and electronic configurations of their cations. The origin of this behaviour is generally thought to be the attenuation of the differences among the $\mathrm{M}^{2+}$ ions caused by their strongly-bound hydration shell(s). Although the present values of $V_{\phi}\left(m^{1 / 2}\right)$ and $C_{p \phi}\left(m^{1 / 2}\right)$ differ among the three salts, their shape is virtually the same. This can be seen most clearly in Figures 5 and 6 which plot all the selected $V_{\phi}$ and $C_{p \phi}$ values for the present divalent metal sulfates, adjusted with arbitrary (empirical) fixed addends. The average spread among the values so adjusted is of the order of $\pm 0.4 \mathrm{~cm}^{3} \cdot \mathrm{mol}^{-1}$ for $V_{\phi}$ and \pm 1 $\mathrm{J} \cdot \mathrm{K}^{-1} \cdot \mathrm{mol}^{-1}$ for $C_{p \phi}$.

This singular behavior is of more than just academic interest: for example, it could be used to provide reliable estimates of the properties of difficult-to-measure sulfate systems, such as $\mathrm{Fe}(\mathrm{II})$ and $\mathrm{Cr}(\mathrm{II})$, with minimal experimental effort. 


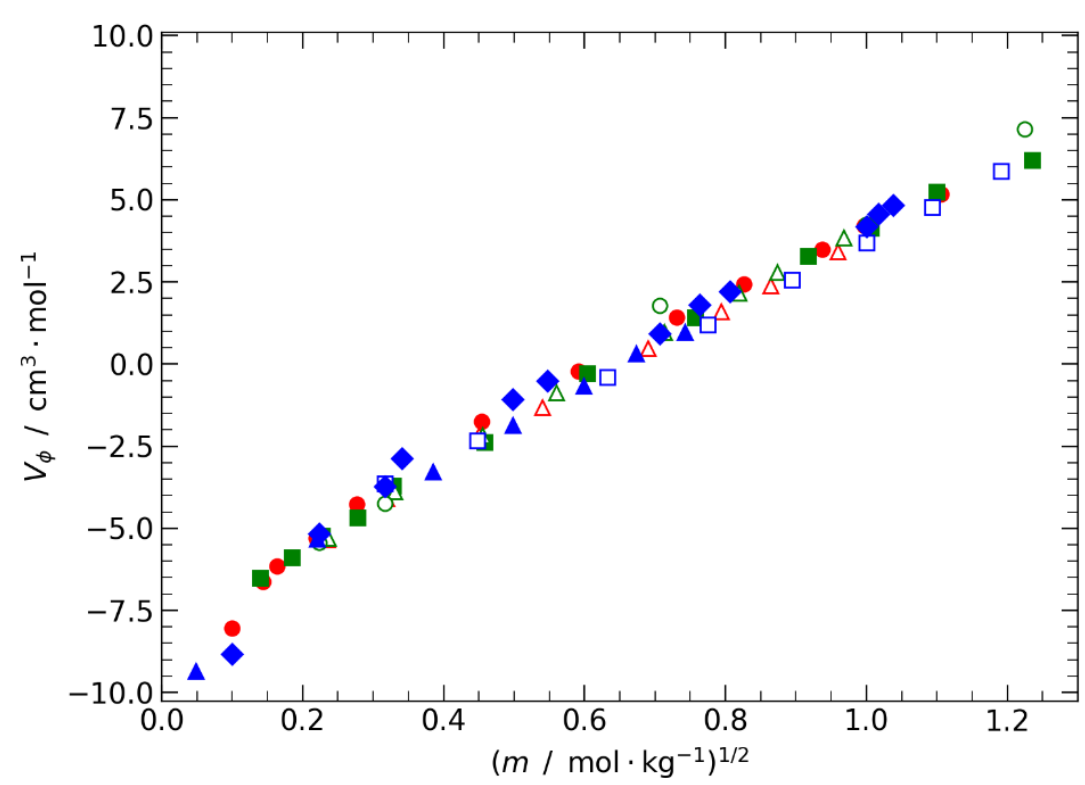

Figure 5. Apparent molar volumes $V_{\phi}$ of $\mathrm{Co}(\mathrm{II}), \mathrm{Ni}(\mathrm{II})$ and $\mathrm{Cu}(\mathrm{II})$ sulfates in aqueous solution at $298.15 \mathrm{~K}$ and $0.1 \mathrm{MPa}$. Present results: red $\bullet, \mathrm{CoSO}_{4}(\mathrm{aq})$; green $\mathbf{m}, \mathrm{NiSO}_{4}(\mathrm{aq})$; blue $\bullet$, $\mathrm{CuSO}_{4}(\mathrm{aq})$; with fixed addends of $-1.2,0$ and $+3.5 \mathrm{~cm}^{3} \cdot \mathrm{mol}^{-1}$, respectively. Other symbols refer to selected literature data (Figures 1,2 and 3) with the same addends.

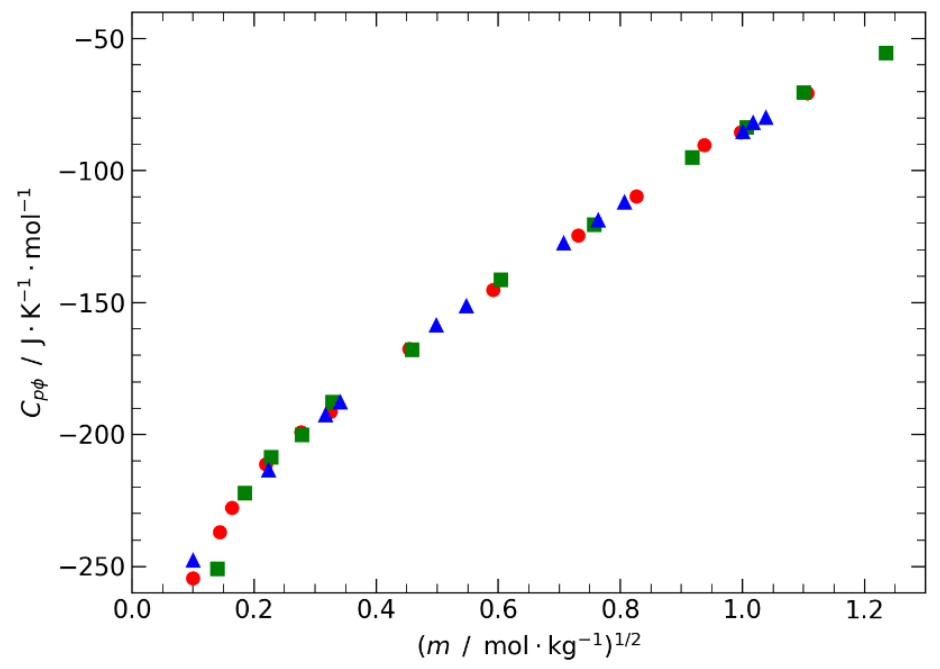

Figure 6. Apparent molar isobaric heat capacities, $C_{p \phi}$ of $\mathrm{Co}(\mathrm{II}), \mathrm{Ni}(\mathrm{II})$ and $\mathrm{Cu}(\mathrm{II})$ sulfates in aqueous solution at $298.15 \mathrm{~K}$ and $0.1 \mathrm{MPa}$ : red $\bullet, \mathrm{CoSO}_{4}(\mathrm{aq})$; green $\mathbf{\bullet}, \mathrm{NiSO}_{4}(\mathrm{aq})$; blue $\bullet$, $\mathrm{CuSO}_{4}(\mathrm{aq})$; with fixed addends of $-60.2,0$ and $+18.7 \mathrm{~J} \cdot \mathrm{K}^{-1} \cdot \mathrm{mol}^{-1}$, respectively. 


\section{CONCLUSIONS}

Apparent molar volumes and heat capacities of aqueous solutions of cobalt(II), nickel(II) and copper(II) sulfate have been determined at $298.15 \mathrm{~K}$ over wide concentration ranges using vibrating tube densimetry and flow calorimetry, respectively. For volumes the present results for all three salts are in good agreement with reliable literature data. No heat capacity data appear to have been reported previously for these sysytems. The values of $V_{\phi}$ and $C_{p \phi}$ over the entire concentration range investigated were well fitted using Pitzer equations by utilizing literature values of the standard quantities $V^{\mathrm{o}}$ and $C_{p}{ }^{\mathrm{o}}$. The three salts show remarkable similarities in the concentration dependence of both $V_{\phi}$ and $C_{p \phi}$, which can be made to lie on single curves over most of the studied concentration range by using empirical fixed addends.

\section{ASSOCIATED CONTENT}

\section{Supporting Information}

Empirical equations relating solution densities $(\rho)$ and isobaric massic heat capacities $\left(c_{p}\right)$ to solute molality $(m)$ for $\mathrm{CoSO}_{4}(\mathrm{aq}), \mathrm{NiSO}_{4}(\mathrm{aq})$ and $\mathrm{CuSO}_{4}(\mathrm{aq})$.

\section{AUTHOR INFORMATION}

\section{Corresponding Author}

*E-mail: g.hefter@murdoch.edu.au; Tel: +61893602226.

\section{ORCID}

Glenn Hefter: 0000-0001-9388-2783

Peter May: 0000-0003-0434-3855

Gamini Senanayake: 0000-0002-4073-4266

Tuomas Vielma: 0000-0003-3598-9042

\section{Funding}

This work was funded by Murdoch University and (for T. V.) the Walter Ahlström Foundation, Finland.

\section{Notes}

The authors declare no competing financial interest.

\section{REFERENCES}

(1) Burkin, A. R. Chemical Hydrometallurgy. Imperial College Press: London, 2001.

(2) Whittington, B. I.; Muir, D. Pressure acid leaching of nickel laterites: A Review. Min. Process. Extractive Metall. Rev. 2000, 21, 527-599.

(3) Wassink, B.; Asselin, E., Eds., Copper Hydrometallurgy: Principles and Practice, Can. Inst. Mining Metall. Petrol.: Toronto 2020 (Electronic Handbook).

(4) Jacobs, J. A.; Lehr, J. H.; Testa, S. M., Eds., Acid Mine Drainage, Rock Drainage, and Acid Sulfate Soils, Wiley-Blackwell: Hoboken, USA, 2014.

(5) Robinson, R. A.; Stokes R. H. Electrolyte Solutions, $2^{\text {nd }}$ ed.; Butterworths: London, 1970.

(6) Criss, C. M.; Millero, F. J. Modeling heat capacities of high valence-type electrolyte solutions with Pitzer's equations. J. Solution Chem. 1999, 28, 849-864. 
(7) Ullmann's Encyclopedia of Industrial Chemistry; Ullmann, F.; Gerhartz, W., Eds.; WileyVCH: Weinheim, Germany, 2000.

(8) Thomas, P. J. Simulation of Industrial Processes for Control Engineers. ButterworthHeinemann: London, 1999.

(9) Wagner, W.; Pruß, A., The IAPWS formulation 1995 for the thermodynamic properties of ordinary water substance for general and scientific use. J. Phys. Chem. Ref. Data 2002, 31, 387-535.

(10) Weast, R. C.; Astle, M. J.; Beyer, W. H., eds, CRC Handbook of Chemistry and Physics, 69th ed., CRC Press: Boca Raton, USA, 1988.

(11) Brown, P. L.; Ekberg, C. Hydrolysis of Metal Ions. Wiley-VCH: Weinheim, Germany, 2016.

(12) Hefter, G.; Gumiński, C. Remarks on the evaluation of thermodynamic data for sulfate ion protonation. J. Solution Chem. 2019, 48, 1657-1670.

(13) Schwarzenbach, G.; Flaschka, H. Complexometric Titrations, $2^{\text {nd }}$ ed.; Methuen: London, 1969.

(14) Chen, T., Ph. D. Thesis, Murdoch University, Australia, 2003.

(15) Magalhães, M. C. F.; Königsberger, E.; May, P. M.; Hefter, G., Heat capacities of concentrated aqueous solutions of sodium sulfate, sodium carbonate, and sodium hydroxide at 25 C. J. Chem. Eng. Data 2002, 47, 590-598.

(16) Archer, D. G. Thermodynamic properties of the $\mathrm{NaCl}+\mathrm{H}_{2} \mathrm{O}$ system. II. Thermodynamic properties of $\mathrm{NaCl}(\mathrm{aq}), \mathrm{NaCl} \cdot 2 \mathrm{H}_{2} \mathrm{O}(\mathrm{cr})$, and phase equilibria. J. Phys. Chem. Ref. Data 1992, 21, 793-829.

(17) Joint Committee for Guides in Metrology. Evaluation of measurement data - Guide to the expression of uncertainty in measurement. International Bureau of Weights and Measures, Saint-Cloud, France, 1995.

(18) Kianinia, Y.; Hnedkovsky, L.; Senanayake, G.; Akilan, C.; Khalesi, M. R.; Abdollahi, M.; Darban, A. K.; Hefter, G. Heat capacities of aqueous solutions of $\mathrm{K}_{4} \mathrm{Fe}(\mathrm{CN})_{6}, \mathrm{~K} 3{ }_{3} \mathrm{Fe}(\mathrm{CN})_{6}$, $\mathrm{K}_{3} \mathrm{Co}(\mathrm{CN})_{6}, \mathrm{~K}_{2} \mathrm{Ni}(\mathrm{CN})_{4}$ and $\mathrm{KAg}(\mathrm{CN})_{2}$ at 298.15 K. J. Chem. Eng. Data, 2018, 63, 1773-1779. (19) Lo Surdo, A.; Millero, F. J. The volume and compressibility change for the formation of transition metal sulfate ion pairs at $25^{\circ} \mathrm{C}$, J. Solution Chem. 1980, 9, 163-181.

(20) Cantelo, R. C.; Phifer, H. E. Partial molal volumes of cobalt sulfate and of cadmium iodide. J. Am. Chem. Soc. 1933, 54, 1333-1338.

(21) Isono, T., Measurements of density, viscosity and electrolytic conductivity of concentrated aqueous electrolyte solutions. I. $\mathrm{LiCl}, \mathrm{NaCl}, \mathrm{KBr}, \mathrm{RbCl}, \mathrm{CsCl}, \mathrm{MgSO}_{4}, \mathrm{ZnSO}_{4}$, and $\mathrm{NiSO}_{4}$, Rikagaka Kenkyusho Hokoku 1980, 56, 103-114 (Chem. Abstr., 1981, 95, 87102t).

(22) Pearce, J. N.; Pumplin, G. G. The apparent and partial molal volumes of ammonium chloride and of cupric sulfate in aqueous solution at $25^{\circ}$. J. Am. Chem. Soc. 1937, 59, 1221 1222.

(23) Puchalska, D.; Atkinson, G.; Routh, S. Solution thermodynamics of first-row transition elements. 4. Apparent molal volumes of aqueous $\mathrm{ZnSO}_{4}$ and $\mathrm{CuSO}_{4}$ solutions from 15 to $55^{\circ} \mathrm{C}$. J. Solution Chem. 1993, 22, 625-639.

(24) Vielma, T.; Hnedkovsky, L.; Hefter, G. unpublished.

(25) Marcus, Y., Ion Properties. Dekker: New York, 1997. 
(26) Spitzer, J. J.; Singh, P. P.; Olofsson, I. V.; Hepler, L. G. Apparent molar heat capacities and volumes of aqueous electrolytes: $\mathrm{CaCl}_{2}, \mathrm{Cd}\left(\mathrm{NO}_{3}\right)_{2}, \mathrm{CoCl}_{2}, \mathrm{Cu}\left(\mathrm{ClO}_{4}\right)_{2}, \mathrm{Mg}\left(\mathrm{ClO}_{4}\right)_{2}$, and $\mathrm{NiCl}_{2}$. J. Solution Chem. 1978, 7, 81-86.

(27) Kapustinskii, A. F.; Yakushevskii, B. M.; Drakin, S. I. Adiabatic calorimeter for measuring heat capacity of solutions. Investigation of salts of $\mathrm{Co}^{++}, \mathrm{Ni}^{++}, \mathrm{Be}^{++}$, and $\mathrm{Ag}^{+}$.

Zh. Fiz. Khim. 1953, 27, 588-595.

(28) Höffler, F.; Steiger, M. Thermodynamic properties of $\mathrm{CuSO}_{4}(\mathrm{aq})$ from $268 \mathrm{~K}$ to $377 \mathrm{~K}$ and phase equilibria in the $\mathrm{CuSO}_{4}-\mathrm{H}_{2} \mathrm{O}$ system. Monatsh. Chem. 2017, 149, 369-379.

(29) Hefter, G. Molar volumes of electrolyte solutions. In Volume Properties: Liquids, Solutions and Vapours, Wilhelm, E.; Letcher, T. M., Eds., RSC Publishing: Cambridge, UK, pp. 493-511, 2015.

(30) Perron, G.; Desnoyers, J. E.; Millero, F. J. Apparent molal volumes and heat capacities of some sulfates and carbonates in water at $25^{\circ} \mathrm{C}$. Can. J. Chem. 1975, 53, 1134-1138.

(31) $\mathrm{Hu}$, B.; Hnedkovsky, L.; Li, W.; Hefter, G. Densities and molar volumes of aqueous solutions of $\mathrm{LiClO}_{4}$ at temperatures from $293 \mathrm{~K}$ to $343 \mathrm{~K}$. J. Chem. Eng. Data 2016, 61, 13881394.

(32) Pitzer, K. S. Ion interaction approach: theory and data correlation. In Activity Coefficients in Electrolyte Solutions, Pitzer, K. S., Ed., $2^{\text {nd }}$ ed., CRC Press: Boca Raton, USA, 1991.

(33) Marcus, Y. The standard partial molar volumes of ions in solution. Part 4. Ionic volumes in water at 0-100 ${ }^{\circ}$ C. J. Phys. Chem. B 2009, 113, 10285-10291.

(34) Rowland, D.; Königsberger, E.; Hefter, G.; May, P. M. Aqueous electrolyte solution modelling: some limitations of the Pitzer equations. Appl. Geochem. 2015, 55, 170-183.

(35) Chen, T.; Hefter G.; Buchner, R. Ion association and hydration in aqueous solutions of nickel(II) and cobalt(II) sulfate. J. Solution Chem. 2005, 34, 1045-1066.

(36) Akilan, C.; Hefter, G.; Rohman, N.; Buchner, R. Ion association and hydration in aqueous solutions of copper(II) sulfate from $5{ }^{\circ} \mathrm{C}$ to $65{ }^{\circ} \mathrm{C}$ by dielectric spectroscopy. J. Phys. Chem. B, 2006, 110, 14961-14970.

(37) Bottomley, G. A.; Glossop, L. G.; Staunton, W. P. Dilatometer studies of the apparent molar volume limiting law for high-charge electrolytes. Aust. J. Chem. 1979, 32, 699-708.

(38) Millero, F. J.; Masterton, W. L. Volume change for the formation of magnesium sulfate ion pairs at various temperatures. J. Phys. Chem. 1974, 78, 1287-1294.

(39) Côté, J.-F.; Desnoyers, J. E.; Justice, J.-C. Application of the Bjerrum association model to volumes of electrolytes in water and acetonitrile. J. Solution Chem. 1996, 25, 113-134.

(40) Fernandez, D. P.; Goodwin, A. R. H.; Lemmon, E. W.; Levelt Sengers, J. M. H.; Williams, R. C. A formulation for the static permittivity of water and steam at temperatures from $238 \mathrm{~K}$ to $873 \mathrm{~K}$ at pressures up to $1200 \mathrm{MPa}$, including derivatives and Debye-Hückel coefficients. J. Phys. Chem. Ref. Data 1997, 26, 1125-1166.

(41) Martell, A. E.; Hancock, R. D. Metal Complexes in Aqueous Solutions. Springer: New York, 2013.

(42) Hefter, G. When spectroscopy fails: the measurement of ion pairing. Pure Appl. Chem., 2006, $78,1571-1586$. 


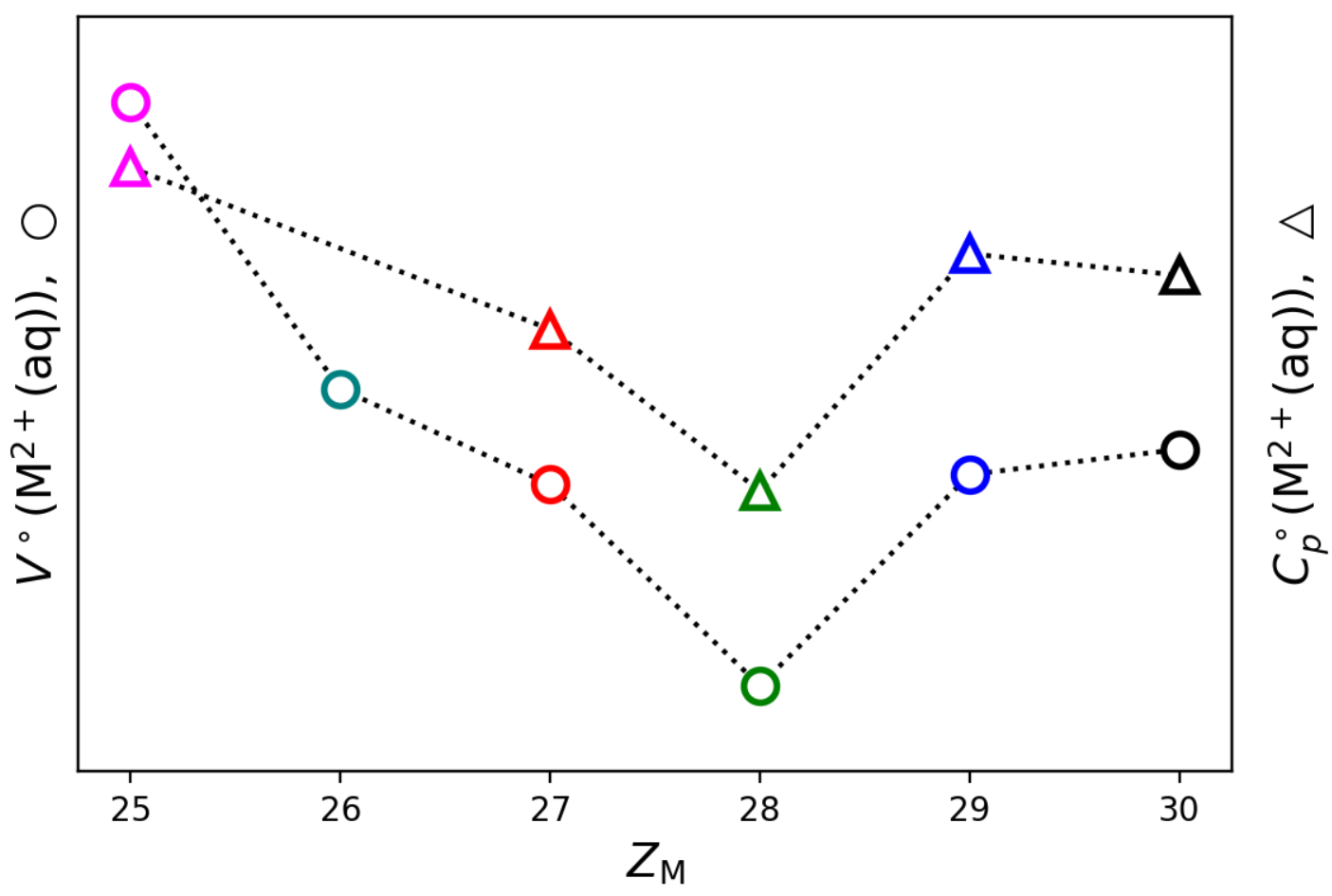

for Table of Contents use only 